\title{
Análisis sociopolíticos de realidades nacionales en la obra de Agustín Cueva en la intersección de los años sesenta y setenta: Ecuador y Chile
}

\section{Sociopolitical analysis or national realities in the work of Agustín Cueva in the intersection of sixties and seventies: Ecuador and Chile}

\author{
Andrés Tzeiman* \\ “(...) siendo la mira inmediata del proletariado la conquista del poder político, su exaltación a \\ clase nacional, a nación, es evidente que también reside en él un sentido nacional (...)". \\ (Karl Marx y Federico Engels, en Manifiesto Comunista)

\begin{abstract}
"Marx, con el fuego de su pensamiento poderoso, ha iluminado después de él todas las revoluciones. Pero el marxismo como tal no ha producido nunca una revolución. Ello ha ocurrido, en cambio, cuando el marxismo ha leído en la historia nacional la forma subterránea de la revolución".

(René Zavaleta, en Ni piedra filosofal ni summa feliz)
\end{abstract}

\begin{abstract}
Resumen: El presente trabajo pretende recuperar las principales conceptualizaciones de una etapa particular de la obra del sociólogo ecuatoriano Agustín Cueva, quien representa una de las figuras más importantes de las ciencias sociales latinoamericanas en la segunda mitad del Siglo XX. Nos dedicaremos a indagar en los análisis sociopolíticos de realidades nacionales (de Chile y Ecuador) que Cueva desarrollara en la intersección de las décadas de 1960 y 1970, un momento de su obra que creemos no ha sido suficientemente explorado.
\end{abstract}

Palabras clave: 1) Agustín Cueva; 2) Análisis sociopolítico; 3) Ecuador; 4) Chile.

\begin{abstract}
This article aims to recover the main conceptualizations of a particular stage of the work of the Ecuadorian sociologist Agustín Cueva, who represents one of the most important figures of Latin American social sciences in the second half of 20th century. We will see sociopolitical analysis of national realities (Chile and Ecuador) that Cueva developed in the intersection of the 1960s and 1970s, a moment of his work that we consider has not been sufficiently explored.
\end{abstract}

Key words: 1) Agustín Cueva; 2) Sociopolitical analysis; 3) Ecuador; 4) Chile

Recibido: 19 octubre 2017

Aceptado: 8 diciembre 2017

* Argentina. Lic. en Ciencia Política y docente en la Carrera de Ciencia Política (Universidad de Buenos Aires, UBA Argentina). Becario Doctoral del Consejo Nacional de Investigaciones Científicas y Técnicas (CONICET, Argentina) por el Instituto de Estudios de América Latina y el Caribe (IEALC-UBA). Correo electrónico: andrestzeiman@hotmail.com 


\section{Introducción}

El sociólogo ecuatoriano Agustín Cueva ha sido, desde nuestro punto de vista, una de las figuras más destacadas de las ciencias sociales latinoamericanas en la segunda mitad del Siglo XX. No solo por el carácter prolífico de su obra, que incluye numerosos trabajos, sino también por haber legado escritos clásicos del pensamiento crítico en la región, como su célebre libro "El desarrollo del capitalismo en América Latina", publicado originalmente en 1977. Vale señalar que éste último fue editado en trece oportunidades por la prestigiosa casa editorial Siglo XXI y galardonado con el Premio Ensayo de ese mismo sello editor. Además, el mismo trabajo fue traducido inéditamente a idiomas como el japonés, el chino y el coreano $^{1}$. Como si esto fuera poco, también Cueva participó y animó calurosos debates intelectuales latinoamericanos, como aquel que se produjera a propósito de las teorías de la dependencia a partir de su artículo de 1974 titulado "Problemas y perspectivas de la teoría de la dependencia", en el que propuso la primera discusión sistemática con ese conjunto de teorías por medio de un diálogo crítico con autores de la talla de Fernando H. Cardoso y Enzo Faletto, André Günder Frank, Francisco Weffort, Theotonio dos Santos, Ernesto Laclau y Vania Bambirra, entre otros ${ }^{2}$.

No obstante, en estas páginas trataremos de desplazarnos de las reflexiones de Agustín Cueva citadas en el párrafo anterior, que seguramente resulten las más conocidas de su obra. Las cuales, además, remiten fundamentalmente al período de "latinoamericanización" de su pensamiento, cuando Cueva ya había abandonado su tierra natal y residía académicamente en la Universidad Nacional Autónoma de México (UNAM) del país azteca. Más bien aquí intentaremos recuperar algunos escritos situados en la bisagra de los años sesenta y setenta, en los que el sociólogo ecuatoriano se dedicó a realizar análisis sociopolíticos de realidades nacionales, abordando específicamente los casos de Ecuador y Chile. Pues consideramos que esos escritos han sido insuficientemente explorados, y al mismo tiempo, contienen interesantes herramientas de interpretación para la comprensión de nuestro presente.

Situándonos ya entonces en el grupo de trabajos de Cueva que quisiéramos abordar en este artículo, debemos comenzar diciendo que tras realizar sus estudios de posgrado en París en la Ecole des Hautes Etudes en Sciences Sociales (entre 1960 y 1963) y dedicarse centralmente en sus escritos de juventud al problema del arte y la cultura en la historia de Ecuador (cuyo corolario fue su primer libro, publicado en 1967, con el título "Entre la ira y la esperanza"3) el sociólogo ecuatoriano comenzó a dirigir sus reflexiones hacia los

\footnotetext{
${ }^{1}$ Báez, René, "Presentación", en Autoritarismo y fascismo en América Latina, Quito, Centro de Pensamiento Crítico, 2013, p. 10.

${ }^{2}$ Un panorama completo de la inserción de Cueva en el debate con los autores del universo dependentista, se puede hallar en: Beigel, Fernanda, Agustín Cueva: Estado, sociedad y política en América Latina, Quito, Casa de la Cultura Ecuatoriana, 1995, pp. 69-113.

${ }^{3}$ Para una interpretación acerca de esa etapa del pensamiento de Cueva y del papel de la literatura en su obra, se puede consultar: Beigel, Fernanda, "Política, ideología y literatura en la obra de Agustín Cueva", en Fernández, Estela María (Comp.), Itinerarios del socialismo en América Latina, Córdoba, Alción Editora, 2001, pp. 183-194.
} 
fenómenos políticos más relevantes de su país de origen. Tal es así que en el año 1967 en la Revista "Indoamérica", escribiría un artículo acerca del velasquismo (en referencia a los distintos gobiernos de José María Velasco Ibarra, a los que nos dedicaremos en las siguientes páginas de este trabajo $)^{4}$. Luego, en el año 1969, en la Revista "Hora Universitaria" de la Universidad Central de Quito (institución en donde fue Director de la Escuela de Sociología y Ciencias Políticas), publicaría otro trabajo sobre la realidad política de Ecuador, esta vez abocado a analizar la crisis económica y social desatada en ese país en los años sesenta ${ }^{5}$. Y ese interés por la política ecuatoriana no cesaría, a pesar de que tempranamente (en 1970) abandonara su país de origen para no regresar por un largo período de tiempo. Más bien continuaría, reflejándose en aquel que sería uno de los libros más importantes en la trayectoria intelectual de Cueva: "El proceso de dominación política en Ecuador", publicado por primera vez en el año 1972. Probablemente ese trabajo sea la expresión más acabada de sus estudios sociopolíticos sobre la realidad ecuatoriana desarrollados en este período.

Al mismo tiempo, aun cuando no haya sido el producto de un trabajo sistemático como lo fueran sus estudios acerca del caso ecuatoriano, en los comienzos de los años setenta también Cueva publicaría un escrito destinado al análisis de otra realidad nacional. En la primera mitad de ese decenio, más precisamente en 1974, escribiría un artículo dedicado a reflexionar, a modo de balance, sobre el proceso político chileno de la Unidad Popular 6 . Recordemos que entre 1970 y 1972, es decir, inmediatamente antes de recalar y trabajar los últimos veinte años de su vida en la UNAM, el autor al que nos estamos refiriendo vivió y cumplió labores en docencia e investigación en el país trasandino (más específicamente, como profesor de Teoría Literaria en la Universidad de Concepción), nutriéndose allí de las lecciones que aquella experiencia política brindaba a los sectores populares latinoamericanos.

Este artículo se dedicará entonces -como señala el título- a indagar en los análisis sociopolíticos de Cueva sobre las realidades nacionales de Ecuador y Chile. En ese sentido, trataremos de reponer el hilo general de aquellas reflexiones, con dos objetivos. Por una parte, intentaremos rescatar sus aportes conceptuales a la realización de análisis en clave de teoría

\footnotetext{
${ }^{4}$ Ese artículo se tituló Más allá de las palabras. Introducción a la mitología velasquista, y fue publicado en el número 7-8 de Indoamérica. Véase Tinajero, Fernando, “Agustín Cueva, o la lucidez apasionada”, en Agustín Cueva. Ensayos sociológicos o políticos, Quito, Ministerio de Coordinación de la Política y Gobiernos Autónomos Descentralizados, 2012, p. 15.

${ }^{5}$ Dicho trabajo, titulado La crisis de los años 60, reaparecería luego en el volumen colectivo denominado Ecuador: pasado y presente, publicado por primera vez en el año 1975. En ese libro también participarían con artículos de su autoría los siguientes intelectuales ecuatorianos: René Báez, Leonardo Mejía, José Moncada, Alejandro Moreano y Fernando Velasco. Véase VV.AA., Ecuador: pasado y presente, Quito, Libresa, 1995. ${ }^{6}$ Además de este artículo, Cueva escribió un año antes, en 1973, otro trabajo acerca del proceso político en el país trasandino, precisamente titulado "Chile" (Véase Cueva, Agustín, "Chile”, en VV.AA., Radicalización y golpes de estado en América Latina, México, UNAM, 1973). Sin embargo, para el análisis que realizaremos en este capítulo nos remitiremos solo a otro artículo de su autoría, denominado "Dialéctica del proceso chileno: 1970-1973", pues creemos que en él se encuentran no solo totalmente contenidas, sino también más ampliamente desarrolladas, las principales ideas e hipótesis planteadas en el mencionado escrito producido con un año de anterioridad.
} 
política. Consideramos que en estos trabajos son utilizadas relevantes categorías cuyo propósito es el de comprender la dimensión específicamente política de los fenómenos sociales, colocando especial atención sobre la autonomía relativa de lo político y de lo ideológico en los procesos sociales. En particular, destacaremos en ellos la centralidad otorgada por nuestro autor a la relación entre Estado y clases sociales como elemento crucial del estudio de las sociedades latinoamericanas. Por lo tanto, a la hora de reconstruir los argumentos desarrollados en los textos de referencia, nos focalizaremos en rescatar los conceptos de teoría política en ellos puestos en valor.

Por otra parte, llevaremos a cabo una distinción entre los análisis de Ecuador y Chile. Una distinción que no le adjudicamos a Cueva, sino que ensayaremos nosotros, en función de la centralidad que otorgamos a sus análisis de coyuntura en clave nacional. Nos detendremos para ello en la forma disímil en que en sendos textos es comprendida tanto la historia de los sectores populares, como sus proyecciones como alternativa de poder. Observaremos que la utilización de elementos teóricos no tendrá la misma productividad en ambos estudios, de acuerdo con la forma desigual en que en cada uno de esos países se constituyeron los sujetos políticos subalternos. De acuerdo con los propósitos señalados, comenzaremos entonces por los trabajos dedicados al análisis de la realidad ecuatoriana.

\section{Ensayos de interpretación de la realidad ecuatoriana}

En 1928 José Carlos Mariátegui escribió una obra que se convertiría en un parteaguas en el pensamiento crítico latinoamericano. Tal es así que sus célebres "Siete ensayos de interpretación de la realidad peruana" pueden ser considerados como el momento fundacional del marxismo latinoamericano, en la medida en que significaron una verdadera lección acerca de cómo la herencia teórica de Marx y Engels debía ser realizada en el análisis de las sociedades de nuestra región. Es decir, utilizando las categorías de los autores clásicos del marxismo, mas respetando la historia y los sujetos históricos de la transformación presentes en una formación económico-social.

En ese sentido, en un artículo titulado "El marxismo latinoamericano: historia y problemas actuales", Cueva señala aquella que para él fuera la gran virtud de José Carlos Mariátegui:

¿En qué radica entonces la grandeza de JCM [José Carlos Mariátegui]? Ante todo, en habernos legado el primer esquema marxista de interpretación de las modalidades específicas de desarrollo del capitalismo en América Latina (...) Al hacerlo, JCM ligó por vez primera el discurso marxista a nuestra realidad, evitando que aquel discurso flotara como una sustancia etérea incapaz de incorporarse al referente empírico que pretende explicar. ¿Nacionalización del marxismo? Si se quiere, sí ${ }^{7}$.

\footnotetext{
${ }^{7}$ Cueva, Agustín, "El marxismo latinoamericano: historia y problemas actuales", en Ideología y sociedad en América Latina, Montevideo, Ediciones de la Banda Oriental, 1988, p. 13.
} 
Pues bien, creemos que en el conjunto de su obra Cueva se hace carne de aquellas indicaciones. Pero al mismo tiempo, consideramos que existe en particular un trabajo suyo que (aun cuando no de forma expresa, y quizá, tampoco deliberada) tiene una inspiración en aquella vocación de los siete ensayos mariateguianos por ligar el discurso marxista a nuestra realidad, nacionalizando el marxismo. Nos referimos a "El proceso de dominación política en Ecuador". Un libro cuyo propósito fue el de hacer un análisis sociopolítico de la sociedad ecuatoriana, remontándose históricamente a la ruptura del orden colonial, para llevar adelante un recorrido que llegara a los fenómenos contemporáneos a la redacción de ese texto, en los inicios de la década del setenta. En ese sentido, nuestro propósito en este apartado será repasar de forma breve dicho trabajo (respetando la cronología histórica presentada por el propio autor), tratando de destacar aquellos aspectos que significan aportes en términos de teoría política, marcando a su vez ciertos límites conceptuales allí encontrados.

Como decíamos en el párrafo precedente, "El proceso de dominación política en Ecuador" tiene como punto de partida la ruptura del orden colonial. Aquel momento histórico es definido por Cueva fundamentalmente como aquello que no es, es decir, como negación de la revolución popular. La independencia ecuatoriana es entendida como una exitosa insurrección de los marqueses criollos contra la Corona de España, que implicó por lo tanto "el último día de despotismo y el primero de lo mismo". Pues no significó el fin de la opresión, sino más bien la sustitución en sus agentes, desplazándose desde el funcionario metropolitano hacia el encomendero criollo. Esta situación tendría importantes consecuencias en el desarrollo del Ecuador, lo cual se expresa en el análisis de nuestro autor en su lectura de las transformaciones que la independencia generaría en el seno de las clases dominantes del país. Es que en la medida en que la ruptura con la metrópoli permitió la eliminación de las restricciones en el comercio exterior, ese proceso habilitaría el aumento de la actividad económica en el agro costeño, conformándose allí a partir de ese momento un importante sector financiero.

Este resquebrajamiento de la estructura social heredada de la colonia, producido en el posindependentismo, significaría la incipiente conformación de una nueva estructura de clases en Ecuador. Cueva sostiene que en ese momento se constituye una nueva clase dominante, se genera el embrión de una pequeña burguesía "moderna", y se abren lugar sectores populares que ya no están institucionalizados bajo el dominio eclesiástico, sino en el marco de relaciones sociales de producción capitalistas. Así, se conforma de manera embrionaria una burguesía constituida por propietarios de plantaciones, grandes comerciantes y banqueros; una pequeña burguesía de comerciantes de pequeña escala; y una clase trabajadora de asalariados agrícolas o trabajadores por cuenta propia y subproletarios surgidos en torno a la actividad portuaria de Guayaquil.

Sin embargo, aquello que nos parece más relevante en relación con los cambios producidos por la independencia, es la lectura de Cueva acerca del impacto que aquel fenómeno supone en términos del ejercicio de la dominación en el plano específicamente político. Pues plantea que, pese a los cambios ocurridos como producto del desarrollo costero, los terratenientes de la zona andina siguen conservando la hegemonía política a escala nacional. Esto implica en 
el análisis del sociólogo ecuatoriano en este trabajo, una primera aproximación a la autonomía relativa de lo político, así como a la asincronía que existe entre las distintas esferas de análisis de la vida social. En ese sentido, aquel aspecto que más nos interesa destacar en lo que respecta al estudio del período que se inicia con la independencia y que llega hasta el final del Siglo XIX, es la dislocación señalada por Cueva entre los niveles económico, político e ideológico. Es decir, la convivencia de un predomino de la producción capitalista en la costa en el orden de lo económico, con una prevalencia semi-feudal en el terreno político-ideológico. Una distinción que no es meramente analítica, sino más bien política, en tanto expresa la puja entre las clases dominantes de la costa y la sierra en la etapa mencionada.

No obstante, la historia ecuatoriana tendría un punto de inflexión con la revolución liberal del año 1895. Cueva afirma que dicho suceso resulta un hito histórico, al transferir el poder del Estado a la burguesía agro-exportadora y producirse un quiebre en el predominio conservador hasta entonces vigente. Aquella revolución, según el intelectual ecuatoriano, tuvo el rol de sacudir la superestructura ideológica de Ecuador, al abrir paso a la libertad de expresión y de culto, al laicismo como pauta de acción estatal y a la democratización de la cultura. Pero resultó al mismo tiempo el sembradío de una naciente contradicción. Pues a la vez que la ruptura del orden conservador forjó un contexto favorable para el desarrollo de ciertos grupos medios que en ese marco lograron constituirse como fuerza social autónoma, provocó un clima de tensión en la medida en que la democratización de la revolución liberal no estuvo acompañada de una transformación en la estructura económica. La demostración más cabal de los límites del despliegue popular en el marco del orden liberal estaría expresada en la masacre de Eloy Alfaro en 1912, a manos de las fuerzas derechistas del Ecuador.

A partir de ese año pasaría entonces a consolidarse el orden liberal, pero deshaciéndose ya de su ropaje revolucionario. Es que la burguesía agro-mercantil, una vez que se había afianzado como clase políticamente dominante, ya no tenía interés en mantener la línea ascendente que desarrollara a partir de 1895. En ese sentido, la faceta conservadora que desplegó el orden liberal a partir de 1912 (en el período conocido como "plutocrático"), merece subrayar dos puntos centrales. Por un lado, una vez consolidado el dominio político de la burguesía costeña, Cueva advierte sobre la conciliación de intereses entre dicho sector y los terratenientes conservadores. En primer lugar, al no haber tocado un ápice del régimen de la propiedad agrícola privada. Y, en segundo lugar, al conceder a los terratenientes andinos el predominio a nivel local, mostrando desinterés en trasladar las instituciones políticas y la ideología liberal a la sierra. Por el otro lado, el autor de "Entre la ira y la esperanza" remarca que la burguesía agro-mercantil en este período no compartió el poder del Estado. Esto tiene que ver, desde su perspectiva, con que, en un país lleno de localismos y regionalismos, necesitaba un pleno control estatal para cohesionar los heterogéneos elementos de la sociedad ecuatoriana. De esa manera, optó por un control total del Estado, mas al mismo tiempo, por un fuerte compromiso con los terratenientes serranos, aun bajo el conocimiento de los deseos de aquellos por retornar al poder central ${ }^{8}$.

${ }^{8}$ Cueva, Agustín, El proceso de dominación política en Ecuador, México, Diógenes, 1974, pp. 12-15. 
Pero aquel aspecto que más preocupa a nuestro autor acerca de este período que se ubica entre los años 1895 y 1925 es el reforzamiento de la situación de dependencia del Ecuador, pues el desarrollo agrícola y comercial ligaría mucho más a dicho país con el capitalismo mundial que lo que había ocurrido durante la época colonial. Un fenómeno que se desnudaría por completo con la crisis que en la década del veinte comenzaba a aflorar en Estados Unidos, cuya repercusión a nivel local cumpliría la función de minar la base económica sobre la que se asentaba la dominación política de la burguesía agro-mercantil. Así, en el contexto crítico de los años veinte, el desgaste del dominio económico de aquel sector de la burguesía se encontraría además con otros dos fenómenos sociales emergentes. El primero de ellos, el aumento del grado de organización y agitación del proletariado en el marco de la crisis económica, que tendría como consecuencia en noviembre del año 1922 el estallido de fervorosas insurrecciones populares. La respuesta represiva del régimen obtendría en ese entonces como resultado una verdadera masacre obrera. El segundo fenómeno emergente, como lo señaláramos más arriba, es el de sectores medios (militares, profesionales, intelectuales) que sufrían el notorio contraste entre la democratización cultural y las desigualdades económicas en el orden liberal. De ese modo, se abriría paso el 9 de julio de 1925 el proceso del "reformismo juliano", a través de un golpe de Estado perpetrado por los oficiales de baja graduación del ejército. Un gobierno que no pretendía quitar el poder económico a la burguesía, sino abrir campo a la clase social a la cual representaban aquellos oficiales: la clase media. De esa manera, el reformismo juliano si bien limitó el poder de la burguesía agro-mercantil, debió ceder ante sus presiones. Aun así, pudo implementar algunas reformas laborales en los sectores público y fabril. Mas para ello tuvo que conformar una alianza con la oligarquía terrateniente en vistas de equilibrar fuerzas con la burguesía costeña. El precio que debió pagar como consecuencia de ese pacto fue bastante oneroso: la no intervención en el agro andino.

En ese sentido, Cueva define a esta situación en la cual Ecuador llegaba a la crisis del treinta como un equilibro inestable y precario de fuerzas. Esto significa, desde el punto de vista del análisis en clave de teoría política, una lectura que privilegia la comprensión de lo político como un campo de lucha dirimido en función de relaciones de fuerzas que, por su propia naturaleza, resultan equilibrios inestables en constante transformación.

Ahora bien, arribamos aquí a un momento sustancial en el análisis del Ecuador realizado por Cueva. La fuerte caída de las exportaciones como consecuencia de la aguda crisis económica internacional, va a develar la índole dependiente de dicho país, desatando una profunda crisis política. Los tres actores que hasta entonces habían gobernado la nación, carecían de la fuerza política y social para hacerlo por sí solos: los terratenientes andinos, la burguesía agromercantil y la clase media. Ante este contexto, que el autor llama "crisis de hegemonía", va a emerger un nuevo elemento social -el subproletariado de las urbes- y va a irrumpir aquel fenómeno político que definirá como "el más inquietante del Ecuador contemporáneo", al cual dedicará enormes esfuerzos explicativos: el velasquismo. En 1934, José María Velasco Ibarra ganaría las elecciones presidenciales con el $80 \%$ de los votos, abriendo un surco en la historia de los sucesivos cuarenta años en Ecuador. 
En ese sentido, si bien el recorrido histórico realizado en "El proceso de dominación política en Ecuador" continúa su tránsito por los años treinta hasta llegar al año 1972, aquí nos detendremos en particular en el análisis del velasquismo. No solo por su carácter singular, y por su impacto en el período histórico que va desde 1930 hasta 1972, sino también porque su conceptualización nos permite seguir retratando las características del pensamiento del sociólogo ecuatoriano, y en especial su capacidad para analizar sociopolíticamente el espacio nacional, aun cuando allí aparezcan tensiones que más adelante nos encargaremos de señalar.

Para explicar el velasquismo, Cueva parte de la coyuntura histórica en la que tiene lugar su parición. Así, se remite a la década que transcurre entre 1922 y 1932, en la que, según su perspectiva, fracasan en Ecuador tres fórmulas de dominación política: la liberal (burguesía de Guayaquil), la militar-reformista (pequeño-burguesa) y la conservadora (terratenientes serranos). Se produce entonces en ese período una situación que denomina "vacío de poder", la cual funciona como el terreno abonado para la emergencia del velasquismo. Su aparición obedece, según él, a tres razones. En primer lugar, a la crisis económica del treinta. En segundo término, a una situación en la que el poder social no estaba concentrado en una sola clase social sino en varias. De forma tal que la hegemonía económica estaba en manos de la burguesía agro-mercantil, la ideológica en poder de los terratenientes de la sierra, en un contexto donde se vislumbraba un "arbitro" con posibilidades certeras de intervención política mediante el uso de las armas: la oficialidad de la clase media. El tercer motivo es la existencia de una coyuntura que categoriza como "situación de masas", caracterizada por: 1) Una composición social de las urbes que volvía obsoleta la tradicional política de élites, y donde se hacía necesario tolerar cierto grado de participación popular en la política nacional; 2) El éxodo rural a las urbes, que creaba nuevas áreas de tensión por la conformación de un sector marginal urbano, y por la depresión en los sectores populares de la ciudad; y 3) La conformación de un grupo de específico comportamiento político: el subproletariado 9 .

En ese sentido, Cueva detecta en este contexto en Ecuador un fenómeno extensamente estudiado por la sociología latinoamericana. Nos referimos a la ligazón entre la crisis económica y la situación de masas. De ese modo, observa cómo se produce una transformación en la fisonomía de la sociedad ecuatoriana, fundamentalmente en las urbes, y con ello, cambios determinantes en el comportamiento de los sectores populares que migran del campo a la ciudad. En un texto posterior (pero que, según aclara el propio autor, es una reproducción parcial de un escrito anterior), titulado "La crisis de 1929-1932: un análisis", sostiene que la principal repercusión de la crisis económica estuvo vinculada a la caída de los precios de las exportaciones. Pero al mismo tiempo se encarga de exponer separadamente las consecuencias políticas y sociales de ese proceso. De esa manera, resalta que el efecto social más trascendente de la crisis del treinta en Ecuador es la conformación de un sector marginal urbano, al volcarse hacia allí una transferencia de la desocupación del sector rural que, si bien "descongestionaba" al agro, empezaba a provocar ciertas áreas de tensión en las grandes ciudades. Una situación que también tendría su expresión como crisis política tras la debacle del régimen juliano, sucediéndose diecisiete gobernantes en el mando del Poder

${ }^{9}$ Cueva, op. cit., pp. 75-76. 
Ejecutivo durante la década del treinta. Así, en el transcurso de 1932 cinco presidentes llegarían a ocupar el Palacio de Gobierno, desencadenándose además en agosto de ese año la conocida como "Guerra de los cuatro días", que enfrentó a conservadores y oficiales progresistas de clase media. Dicha crisis política, que Cueva define nuevamente como un "vacío de poder", es para él el caldo de cultivo de la emergencia del velasquismo ${ }^{10}$.

De esa forma, considerando ese contexto económico, político y social, Cueva intenta evitar una explicación del triunfo electoral de 1934 y su derrotero posterior basada simplemente en los rasgos de la personalidad de Velasco Ibarra. Por el contrario, busca anclar el fenómeno en las contradicciones de la sociedad ecuatoriana. Por eso, sostiene: “(...) no es cuestión de un simple fenómeno de caudillismo, reductible a la personalidad del líder, sino de un hecho complejo', profundamente arraigado en la particularidad histórica de la formación social ecuatoriana"11.

Desde el punto de vista de Cueva, ese "hecho complejo" debe ser comprendido a partir de la situación de dependencia, la cual provoca en ocasión de las crisis la acentuación de ciertas contradicciones internas específicas, originadas en la heterogeneidad estructural de la sociedad ecuatoriana. El velasquismo es entonces para el autor de "El proceso de dominación política en Ecuador" una fórmula de "transacción" entre una burguesía agro-mercantil en crisis y una aristocracia terrateniente todavía poderosa, así como también un "medio de manipulación de masas" predominantemente subproletarias ${ }^{12}$. Pero aquella categoría que nos parece más adecuada en la conceptualización del intelectual ecuatoriano es nuevamente la de equilibro precario, como expresión de una situación en donde ni las clases dominantes podían constituir un sistema estable de dominación -surcadas al mismo tiempo por contradicciones intestinas irresolubles-, ni las clases subalternas podían ofrecer una alternativa hegemónica.

Una caracterización que revela una valoración especial por parte de Cueva, también aquí, con respecto a la autonomía relativa de lo político, en tanto reconoce que el velasquismo aun cuando constituye desde lo estatal "la solución más rentable para las clases dominantes"se presentó como opción política en un proceso de tensión permanente con los principales grupos dominantes y partidos políticos representativos de ellos. Dando cuenta de esa forma de una característica definicional del Estado capitalista:

\footnotetext{
${ }^{10}$ Cueva, Agustín, "La crisis de 1929-1932: un análisis", en VV.AA., Las crisis en el Ecuador: los treinta y ochenta, Quito, Corporación Editora Nacional-Centro de Estudios Latinoamericanos de la Universidad de Oxford-Instituto de Estudios Avanzados, 1991, pp. 71-73.

${ }^{11}$ Cueva, op. cit., p. 98. Esta concepción del velasquismo como un "hecho complejo", se asemeja bastante a la forma en que Marx definiera al bonapartismo, negando que éste resultara un "rayo cayendo de un cielo sereno", y anclando su surgimiento, alternativamente, en el desarrollo de las contradicciones sociales francesas. Recordemos las palabras de Marx en el prólogo a la segunda edición de "El 18 Brumario": "Víctor Hugo se limita a una amarga e ingeniosa invectiva contra el editor responsable del golpe de Estado. En cuanto al acontecimiento mismo, parece, en su obra, un rayo que cayese de un cielo sereno. No ve en él más que un acto de fuerza de un solo individuo (...) Yo, por el contrario, demuestro cómo la lucha de clases creó en Francia las circunstancias y las condiciones que permitieron a un personaje mediocre y grotesco representar el papel de héroe". Véase Marx, Karl, El 18 Brumario de Luis Bonaparte, Buenos Aires, Prometeo, 2003, p. 8.

${ }^{12}$ Cueva, op. cit., p. 99.
} 
(...) la respuesta histórica concreta tendiente a la autoconservación del sistema nunca coincide de manera estricta con el proyecto particular de dominación de uno solo de los grupos hegemónicos (clase o fracción de clase). Por este hecho el velasquismo adquiere complejidad y aparece como una fórmula no ortodoxa, casi bastarda de dominación, en la medida en que representa, de una parte, un compromiso entre los proyectos de dominio en competencia y, de otra, una adecuación del conjunto de ellos a las posibilidades objetivas de ejercerlo ${ }^{13}$.

Esta idea de falta de correspondencia entre clases dominantes y Estado, nos remite a la concepción engelsiana del fenómeno estatal, entendido éste último como "capitalista colectivo ideal". Pues el Estado, según su concepción, no responde directamente a una u otra fracción del capital, sino que su función es la de garante de la relación social de capital. Dice Engels en "Del socialismo utópico al socialismo científico":

(...) El Estado moderno no es tampoco más que una organización creada por la sociedad burguesa para defender las condiciones exteriores generales del modo capitalista de producción contra los atentados, tanto de los obreros como de los capitalistas aislados. El Estado moderno, cualquiera que sea su forma, es una máquina esencialmente capitalista, es el Estado de los capitalistas, el capitalista colectivo ideal ${ }^{14}$.

Vemos como punto de coincidencia con respecto a aquella definición de Engels, la aparición temprana en la obra de Cueva de una concepción no instrumentalista del Estado. Pues éste no se presenta precisamente como un instrumento aprehensible por las clases, sino más bien como una estructura organizada en función de la continuidad de un orden social ${ }^{15}$. Un elemento cuya repercusión no se restringe al orden teórico, sino que tiene consecuencias políticas, en la medida en que permite comprender la naturaleza de fenómenos como el velasquismo.

Retomando la lectura sobre la autonomía relativa de las esferas, la misma no se aplica solamente a la región de lo político, sino que se extiende a su vez al campo de lo ideológico. Pues al mismo tiempo, nuestro autor trata de explicar el "caos" ideológico que es atribuido a Velasco Ibarra. Es decir, intenta comprender la mixtura ideológica de un líder que ha llegado a invocar para sí de forma irreverente las tradiciones liberal, católica y socialista. Así, el sociólogo ecuatoriano nos habla de un "relajamiento de la cohesión interna de las ideologías" que es propia de una región como América Latina, donde la adopción de ideas "exóticas", nacidas por fuera de nuestras latitudes, implicó adaptar esos elementos a una realidad tan particular, que se vio obligada a transformarlas. A su vez, repara en que intelectuales y

${ }^{13}$ Cueva, op. cit., p. 81.

${ }^{14}$ Engels, Federico, Del socialismo utópico al socialismo científico, Buenos Aires, Anteo, 1986, p. 95.

${ }^{15}$ A través de esta ligazón con aquellas apreciaciones de Engels intentamos inscribir las reflexiones de Cueva sobre el Estado en toda una tradición al interior del marxismo que ha dedicado sus esfuerzos explicativos a comprender la complejidad del fenómeno estatal y que bien puede remontarse a aquel pensador decimonónico. 
filósofos latinoamericanos han tendido a amalgamar las más diversas ideologías y corrientes de pensamiento, y se pregunta por qué el subproletariado no habría de acudir a ese sincretismo político para sacar "lo mejor" y "más puro" de cada doctrina".

Hasta aquí en este apartado nos hemos referido a aquellos aspectos de "El proceso de dominación política en Ecuador" (y de otros escritos más breves dedicados al análisis sociopolítico de la realidad ecuatoriana) que consideramos como los más salientes en el sentido de aportar elementos teóricos productivos al estudio de la formación económicosocial ecuatoriana. Ahora bien, para finalizar la presente sección de este trabajo, quisiéramos dedicarnos brevemente a señalar algunos pasajes del libro en cuestión en los que son utilizadas ciertas categorías y privilegiadas ciertas concepciones que, según nuestra mirada, sesgan las reflexiones acerca de la relación entre sectores populares y socialismo en la sociedad ecuatoriana.

Creemos que existe un sesgo conceptual que se centra principalmente en la visión acerca de aquel sector de la clase trabajadora que Cueva llama subproletariado. Desde el punto de vista del sociólogo ecuatoriano, el problema del marxismo en Ecuador ha sido la composición netamente subproletaria de los sectores populares, un grupo según él inadecuado para una politización en un sentido revolucionario. Esa preponderancia contrastó con un débil proletariado y un campesinado que nunca pudo ir más allá de jornadas tan heroicas como carentes de perspectiva revolucionaria ${ }^{17}$. Esto ha tenido como consecuencia, según el autor, un desarrollo de las contradicciones sociales en donde la participación alienada del subproletariado en conjunto con la marginalidad política del campesinado, han permitido que el control del Estado se haya desplegado al nivel de las contradicciones secundarias (oposición entre terratenientes y burguesía, emergencia de la clase media, movilización subproletaria).

Según nuestra perspectiva, Cueva incurre en esas conceptualizaciones en cierto reduccionismo teórico que le impide pensar en las disímiles articulaciones que puede significar la construcción de un movimiento popular. Es absolutamente pesimista acerca del sector que denomina subproletariado, rechazando por completo que pueda cumplir un rol progresivo en el plano de la política. Asimismo, es escasa su indagación en el papel desempeñado por las organizaciones de izquierda a la hora de constituir un movimiento de masas capaz de aglutinar a los distintos sectores de las clases subalternas. Contrasta con ello el apego por momentos a un lenguaje que prefiere inclinarse hacia una mirada peyorativa del fenómeno velasquista, antes que tratar de encontrar los motivos del desencuentro entre socialismo y movimiento popular en Ecuador. La idea acuñada por el autor de un régimen de "manipulación de masas", probablemente no resulte el modo más adecuado de conceptualizar el velasquismo, el cual según las características señaladas por el propio autor $-\mathrm{y}$ eso es precisamente lo paradójico de este reduccionismo teórico-, merece mayor complejidad y rigurosidad.

\footnotetext{
${ }^{16}$ Cueva, op. cit., pp. 92-93.

${ }^{17}$ Cueva, op. cit., pp. 78-79.
} 
No tenemos la intención aquí de encontrar una respuesta definitiva o con pretensiones de verdad acerca de los motivos de ese repliegue hacia el discurso teórico que, a nuestro modo de ver, se contrapone a las conceptualizaciones predominantes (fecundas y productivas) sobre el plano específicamente político desplegadas en "El proceso de dominación política en Ecuador". Pero nos permitimos señalar que el notorio contraste al que hacemos referencia, quizá sea producto del análisis de un país donde la lucha de clases no contó con un movimiento popular vigoroso ni con poderosas organizaciones de izquierda que marcaran el rumbo del destino nacional, o que presentaran una alternativa política con verdadera vocación de poder. Tal es así que en "El proceso de dominación política en Ecuador" es un tópico prácticamente ausente la incidencia del movimiento obrero y las organizaciones de izquierda en la historia política nacional. De hecho, resulta interesante remitirnos a un artículo publicado por Cueva en la Revista Mexicana de Sociología en el año 1976, para establecer un contraste histórico y político. Recordemos, en ese sentido, que el tex to sobre el que hemos venido trabajando, publicado en 1972 (y escrito originalmente en 1970), no llega a abordar las contradicciones emergentes ese mismo año con el advenimiento del gobierno del General nacionalista Guillermo Rodríguez Lara ${ }^{18}$. Mientras tanto, en el referido artículo de 1976, es destacada la erección del proletariado como un actor clave en el desenvolvimiento de la crisis del proyecto nacionalista y de las disputas al interior de las clases dominantes: "Y aquí interviene un último factor, que a no dudarlo es el más importante en la coyuntura actual: la presencia del proletariado en la escena política nacional, con una envergadura, una organización, un grado de conciencia y unidad antes inexistentes"19.

Con este contraste queremos subrayar que en "El proceso de dominación política en Ecuador" Cueva deposita de forma exclusiva en las condiciones objetivas del desarrollo capitalista de Ecuador $-\mathrm{y}$ con ellas, en la fisonomía de los sectores subalternos- el papel secundario desempeñado por las clases populares en la historia política de ese país hasta $1970^{20}$. Aun

${ }^{18}$ La edición mexicana de "El proceso de dominación política en Ecuador" que citamos en este trabajo, publicada en 1974, contiene un apéndice escrito por Cueva en el año 1973 ya en el país azteca, titulado "Del 'autogolpe' de 1970 al nuevo régimen militar". Allí se presentan los primeros rasgos del gobierno de Rodríguez Lara, mas no existe un desarrollo acerca del rol de las organizaciones de los trabajadores y de la izquierda en ese proceso.

${ }^{19}$ Véase Cueva, Agustín, "Crisis del capitalismo y perspectivas del nacionalismo en América Latina (análisis del caso ecuatoriano)", en Revista Mexicana de Sociología, Año XXXVIII, Vol. XXXVIII, N4, octubrediciembre, México, 1976, p. 825.

${ }^{20}$ Esta falta de protagonismo de las organizaciones de los sectores populares en la vida política ecuatoriana, según la socióloga mexicana Raquel Sosa Elizaga, fue objeto de duros cuestionamientos por parte de Cueva. En un texto escrito en su memoria para una compilación que realizaran Ruy Mauro Marini y Márgara Millán acerca del derrotero del marxismo en la teoría social latinoamericana, Sosa Elizaga recuerda las posiciones del sociólogo ecuatoriano al respecto: "Fue un duro crítico de las agrupaciones de izquierda de su país, a las que consideraba incapaces de cuestionar el orden establecido. Él se planteaba la necesidad de una opción más clara y convincente, pero no la veía en las distintas organizaciones existentes: tanto el Partido Comunista como los partidos socialistas y los grupos radicales estaban, desde su punto de vista, penetrados por la contradicción que marcaba al conjunto de la vida ecuatoriana, por esta inseguridad respecto a su identidad y a sus planteamientos, lo cual los llevaba unas veces a ser demasiado tibios, y otras a errar en la definición de la estrategia a seguir frente a sus enemigos de clase". Véase Sosa Elizaga, Raquel, "Agustín Cueva en la memoria", en Ruy Mauro 
cuando resulta inobjetable afincar el despliegue de la lucha de clases en determinadas condiciones objetivas de una sociedad, ello no debe constituir un obstáculo para concebir las formas y posibilidades de organización de las clases trabajadoras en un determinado momento histórico. Creemos que la idea de un régimen de "manipulación de masas" más bien conspira contra esa necesidad, e impide comprender los desafíos del movimiento popular en el marco de las condiciones sociales realmente existentes. No pretendemos incurrir en un análisis reduccionista, pero probablemente la similitud con la lectura del bonapartismo no haya resultado la mejor ayuda para superar ese escollo, en la medida en que la figura de Velasco entendida como un árbitro grotesco ubicado excepcionalmente por encima de las clases no resultaba del todo suficiente para una dilucidación de aquel fenómeno político.

Por otra parte, en este aspecto debemos marcar un contrapunto con los "Siete ensayos". Allí, Mariátegui lleva a cabo su ensayo de interpretación de la realidad peruana en el marco de una sociedad eminentemente agraria. Es aquel un momento de crisis, pero todavía de persistencia de la dominación oligárquica, basada principalmente en la propiedad de la tierra. El trabajo de Cueva, por el contrario, es efectuado en el ocaso de la década del sesenta. Nos situamos en sociedades que tal como él mismo lo indica -y nos hemos referido a ello más arriba en este apartado-, han atravesado la irrupción de las masas en la escena política, adquiriendo un nuevo protagonismo en las grandes urbes. Por lo tanto, las soluciones políticas planteadas por el Amauta peruano en sus textos parecen necesitar un aggiornamiento en la bisagra de los años sesenta y setenta. Por eso, entendemos que las dificultades encontradas por Cueva no significan haber desestimado las lecciones de método legadas por Mariátegui acerca de la necesidad de arraigar el marxismo en los sectores populares de cada nación, sino más bien implican haberse enfrentado a una etapa histórica y una realidad nacional en las que la articulación entre socialismo y movimiento popular asumía crecientes complejidades.

Si bien la esbozada en los párrafos anteriores es tan solo una respuesta posible a la tensión entre lenguaje teórico y configuración del movimiento popular en el terreno de la nación, creemos que la comparación con un escrito posterior de Cueva puede resultar un respaldo para ella. Pues observamos en el artículo titulado "Dialéctica del proceso chileno: 19701973" una lectura bien diferente del derrotero organizativo de los sectores populares, y más aún, de los sujetos históricos de la transformación social. Es nuestra estimación que probablemente las diferencias entre los escritos sobre Ecuador y Chile no sean fruto de una casualidad, considerando que el vigor de la clase trabajadora chilena y sus organizaciones sindicales y políticas contrasta notablemente con el del movimiento popular ecuatoriano. Nos abocaremos entonces en las siguientes páginas a analizar el mencionado trabajo sobre el proceso chileno de la Unidad Popular.

Marini y Márgara Millán (Coord.), La teoría social latinoamericana. La centralidad del marxismo, México, Ediciones El Caballito, Tomo III, 1995, p. 299. 


\section{El proceso político chileno: la lucha de clases "con empanadas y vino tinto"}

El golpe de Estado sufrido por Chile el 11 de septiembre de 1973 significó un momento de ruptura en la historia de América Latina, pues marcaría un quiebre en relación con la radicalidad adoptada por los movimientos populares en toda la geografía regional en los años sesenta y comienzos de los años setenta. Además, aquella acción cívico-militar implicó un fuerte aleccionamiento al conjunto de las experiencias revolucionarias de la época, en tanto las fuerzas del orden mostraban sin reparos hasta donde eran capaces de llegar para ponerle un freno a aquel que probablemente haya sido uno de los procesos de transformación social más ricos en la historia de los sectores populares latinoamericanos. En ese sentido, en el artículo titulado "Dialéctica del proceso chileno: 1970-1973" Cueva trata de explicar el recorrido histórico que tuvo lugar en el país trasandino hasta llegar al bombardeo y la ocupación de la Casa de la Moneda por los mandos militares chilenos en 1973. Prestando especial atención allí al desarrollo de la lucha de clases en ese espacio nacional, y remitiéndose para ello a la constitución de la clase obrera como sujeto político central en los comienzos del siglo XX, mas abocándose fundamentalmente al período en que se despliega la experiencia política de la Unidad Popular.

Con el fin de abordar entonces el proceso desplegado entre 1970-1973, el sociólogo ecuatoriano establece como eje de gravedad de su estudio el desarrollo político-organizativo de la clase obrera chilena en el transcurso del Siglo XX. Pues una nota distintiva de este trabajo es precisamente la colocación del énfasis analítico en la constitución de la clase trabajadora al calor de la lucha política. Y este es un elemento inicial que quisiéramos destacar, ya que, si bien el autor se encarga de subrayar inequívocamente en sus trabajos la inscripción de la lucha de clases en un grado determinado de desarrollo de las fuerzas productivas y de las relaciones sociales de producción, en este artículo aparece como un punto nodal la trascendencia de la batalla entre las clases como un aspecto constitutivo en su conformación y desarrollo.

De esa manera, el autor de "El desarrollo del capitalismo en América Latina" comienza este trabajo sobre Chile haciendo un repaso por los hitos en la constitución de la clase obrera de ese país: las huelgas obreras de los trabajadores portuarios y salitreros de 1903 y 1907 respectivamente; la fundación de la Federación Obrera Chilena en 1909; la creación del Partido Obrero Socialista en 1912, el cual se convertiría apenas diez años después, bajo el liderazgo del tipógrafo Luis Emilio Recabarren, en el Partido Comunista de Chile; la conformación del Partido Socialista en 1933, produciéndose a partir de allí la tradicional unidad entre comunistas y socialistas chilenos; la inserción político-institucional de la izquierda con el triunfo del Frente Popular en 1938; y la formidable elección del Frente de Acción Popular en 1958, cosechando apenas 30000 votos menos que Jorge Alessandri, el candidato de la derecha que resultara ganador en esa contienda. Sintetizando ese derrotero, Cueva afirma: 
Es a partir de estos antecedentes que el triunfo de la Unidad Popular en 1970 se nos presenta como la exitosa culminación de una prolongada lucha política, a través de la cual el proletariado no sólo había ido forjando su conciencia y perfeccionando sus organizaciones de clase, sino también aglutinando en torno suyo a otras fuerzas progresistas de la sociedad chilena: intelectuales, sectores de las capas medias y aun de la pequeña burguesía $(\ldots)^{21}$.

El criterio adoptado en ésta que resultara su primera aproximación en el artículo de referencia al recorrido histórico transitado por la clase trabajadora chilena hasta llegar al triunfo electoral de 1970, nos remite a aquel criterio esbozado por Antonio Gramsci en sus "Apuntes sobre la historia de las clases subalternas", redactados en los célebres "Cuadernos de la cárcel”. Dice allí el marxista sardo:

El estudio del desarrollo de estas fuerzas innovadoras desde el estadio de grupos subalternos hasta el de grupos dirigentes y dominantes tiene, por tanto, que buscar e identificar las fases a través de las cuales dichas fuerzas han conseguido la autonomía respecto de los enemigos a los que tenían que derrotar, y la adhesión de los grupos que las han ayudado activa o pasivamente, en la medida en que todo ese proceso era históricamente necesario para que dichas fuerzas se unificaran en estado ${ }^{22}$.

Pues bien, Cueva emprende un recorrido a través de las luchas desarrolladas por la clase trabajadora chilena desde comienzos del siglo XX hasta 1970. Marca los hitos que la fueron constituyendo políticamente como clase, y fundamentalmente, cómo fue adquiriendo autonomía en relación con el resto de las clases, tanto las enemigas como aquellas que se habían presentado circunstancialmente como aliadas. Lo importante aquí es señalar el criterio adoptado, es decir, el eje colocado en el despliegue de la lucha política como la forma en que la clase se constituye como sujeto histórico.

Mas quisiéramos resaltar, además de la memoria larga de la clase trabajadora de Chile, otra cuestión que ocupa un rol protagónico en "Dialéctica del proceso chileno". Nos referimos al contexto previo que precedió de forma inmediata el triunfo de la Unidad Popular. Pues a partir de él se desprende una conceptualización de las clases sociales y de su expresión política, que para nosotros reviste especial interés. Hacemos alusión a aquel momento en el que la política chilena estuvo marcada por el experimento reformista de la democracia cristiana, conocido bajo el nombre de "Revolución en libertad". Las elecciones de 1970 son entonces herederas de un proceso político en donde el proyecto reformista del Partido de la Democracia Cristiana (PDC) -inserto en una coyuntura caracterizada por un elevado nivel de lucha de clases a escala nacional y continental-, asumió un radicalismo verbal que

${ }^{21}$ Cueva, Agustín, "Dialéctica del proceso chileno: 1970-1973", en Teoría social y procesos políticos en América Latina, México, Edicol, 1979, p. 100.

${ }^{22}$ Gramsci, Antonio, "Apuntes sobre la historia de las clases subalternas. Criterios metódicos", en Escritos políticos (1917-1933), México, Siglo XXI, p. 360. 
contrastó notoriamente con las medidas efectivamente implementadas por el gobierno del Presidente Eduardo Frei. De esa forma, señala Cueva, la línea prácticamente reformista pero verbalmente revolucionaria del PDC desencadenaba en los sectores populares una "peligrosa dialéctica de aspiraciones y frustraciones"23. Y al mismo tiempo, producía una izquierdización relativa del contexto político chileno, que tenía efectos específicos en la sociedad, en la medida en que tanto el PDC como el Partido Nacional contenían a otros sectores sociales que no eran necesariamente burgueses. En relación con ello, consideramos que en las apreciaciones de nuestro autor acerca del PDC subyacen ciertos elementos teóricos que merecen ser rescatados. Si bien el intelectual ecuatoriano observa detenidamente el componente social que es propio de aquel partido político más allá de su anclaje en la burguesía industrial urbana (menciona a la tecno-burocracia, los profesionales liberales y ciertos sectores de la "aristocracia obrera" y el campesinado), se encarga especialmente de enfatizar en el carácter heterogéneo del PDC. Ello, debido a que dicha heterogeneidad mucho más escasa en el Partido Nacional- generaba contradicciones que se manifestaban, desde la perspectiva de Cueva, en su ideología y en sus prácticas políticas. Esto implica, desde un punto de vista teórico-político que, si bien la política y la ideología arraigan en las condiciones materiales de existencia, no son un mero "reflejo" de ellas, ni tampoco que de ellas se desprenda una relación necesaria. Más bien creemos, a partir de los señalamientos citados, que el sociólogo ecuatoriano aporta una mirada de lo político y lo ideológico que no supone un tránsito transparente desde lo económico hacia esos niveles, sino más bien un camino complejo, atravesado por contradicciones que constituyen como tal a la totalidad social. Esto supone, pero no se reduce, a la mencionada autonomía relativa de lo político y lo ideológico. Significa más bien abrir un campo de indagación fundamental: el de la hegemonía y la constitución de los sujetos políticos. De esa manera, Cueva señala que uno de los factores más trascendentes en el derrotero del gobierno popular de Salvador Allende fue la capacidad fluctuante de la clase obrera chilena para hegemonizar el proceso político, es decir, para comprender y asimilar como propios los intereses de las bases sociales del PDC.

Asimismo, el papel protagónico desempeñado tanto por la dirección de aquel partido cristiano como por sus bases sociales en los años comprendidos entre 1970 y 1973, oportunamente analizado por Cueva, también revela otro aspecto que él observara con detalle: la forma que asumen las contradicciones de clase. El rol tanto más peligroso en lo político e ideológico que tuvo el PDC en relación con los menores efectos de la acción del Partido Nacional en esos mismos planos, no significa que la contradicción se haya desplazado en relación con los dos campos de antagonismo fundamental en la sociedad capitalista. Más bien implica su plena vigencia, adquiriendo las características específicas que son propias de la historia chilena. Al respecto, rescatamos muy especialmente la siguiente apreciación teórica, cuyo valor, a nuestro modo de ver, excede largamente el análisis de un caso nacional en particular:

${ }^{23}$ Cueva, Agustín, "Dialéctica del proceso chileno: 1970-1973”, en Teoría social y procesos políticos en América Latina, México, Edicol, 1979, pp. 101-102. 
Por demás está decir que jamás se ha dado en país alguno un enfrentamiento "puro", que tenga como únicos y desnudos protagonistas a las dos clases fundamentales de la sociedad capitalista, sino que la contradicción entre éstas se abre paso siempre a través de un enmarañado tejido de múltiples contradicciones y sobredeterminaciones, con puntos diversos de condensaciones, que el desarrollo del antagonismo principal, expresado necesariamente en acciones concretas, atinadas o no, de las fuerzas políticas a través de las cuales se manifiesta, va justamente organizando y reorganizando, al determinar para cada elemento papeles específicos dentro de cada coyuntura concreta ${ }^{24}$.

Por solo nombrar algunos ejemplos, basta mencionar lo sucedido en el proceso chileno con la pequeña burguesía, las capas medias, y principalmente, con el ejército. Todos esos actores tuvieron un rol fundamental en el desarrollo de la experiencia en cuestión, modificándose sus posiciones y su papel en la escena política, según iban mutando las relaciones de fuerza. Esas reorganizaciones y reacomodamientos - Cueva destaca principalmente los del ejército, pasando del tradicional "constitucionalismo" al intervencionismo absoluto- dan cuenta del carácter complejo y muchas veces opaco en que se desarrollan las contradicciones.

Por otra parte, consideramos de suma relevancia las contribuciones realizadas en "Dialéctica del proceso chileno" acerca del fenómeno estatal. Allí Cueva aporta algunos elementos que desarrollan una interesante conceptualización del Estado capitalista. Pues, de un lado, sostiene que el Estado se encuentra penetrado por la lucha de clases, repercutiendo sus efectos por ende en las instituciones estatales. El Estado es entonces expresión de correlaciones de fuerza, desgarrado por la lucha de clases. Ahora bien, del otro lado, subraya que dicha expresión no es neutral, ya que la estatalidad está cargada de una inevitable asimetría, en la medida en que las reglas del juego que lo rigen son las de la sociedad capitalista ${ }^{25}$. Estas apreciaciones revelan entonces la doble dimensión del Estado capitalista: dominación y contradicción.

Asimismo, con respecto a esta segunda dimensión, en este texto se puede observar otro elemento central, que quizá sea distintivo de la estatalidad latinoamericana. Cueva destaca en el escrito de referencia el papel que desempeña el Estado en el proceso chileno. Allí, en lugar de cumplir la función de regular las contradicciones sociales, colocándose por encima

\footnotetext{
${ }^{24}$ Cueva, Agustín, "Dialéctica del proceso chileno: 1970-1973", en Teoría social y procesos políticos en América Latina, México, Edicol, 1979, p. 108.

${ }^{25}$ Dicha asimetría nos recuerda a lo expresado algunos años después por el pensador boliviano René Zavaleta en su artículo titulado "El Estado en América Latina”. Dice allí Zavaleta: “(...) fue Lenin quien sostuvo que el Estado es la síntesis de la sociedad. Se supone que ello quería decir que es el resultado político, su consecuencia revelada como ultimidad pero no que se le viera como un resumen literal de ella, lo cual sería solo una tautología. Hablamos por tanto de una síntesis, pero de una síntesis realizada desde un determinado punto de vista, una síntesis calificada (...) La elaboración de la materia estatal en el plano de la sociedad civil es indiscutible pero el Estado, hay que decirlo, es Estado en la medida en que se reserva el privilegio de dar su propio color o señal a ese mensaje". Véase Zavaleta, René, "El Estado en América Latina", en El Estado en América Latina, La Paz, Los amigos del libro, 1990, p. 172.
} 
de la sociedad y amortiguando los choques entre las clases -como lo conceptualizaran en ciertos textos principalmente Engels y Lenin ${ }^{26}$, se encargaba más bien de reproducir dichas contradicciones en su propio seno. Así, el Estado se convertía en uno de los puntos nodales de la lucha de clases. Una batalla que se expresaba entre políticas gubernamentales destinadas hacia la transformación del modo de producción dominante, y una superestructura encargada de perpetuarlo ${ }^{27}$.

En síntesis, la explicación detallada del proceso chileno, centrándose en la forma específica en que se desenvuelve la lucha de clases en ese país entre 1970 y 1973, nos invita a recuperar y ponderar una manera de analizar los procesos sociopolíticos, que nos devuelve como inspiración teórica a dos textos ilustres de Marx: "Las luchas de clases en Francia" y "El 18 Brumario de Luis Bonaparte". Pues Cueva logra delinear el accionar de las diferentes fracciones de clase, y distinguir la forma singular en que esa lucha se expresa en los campos político e ideológico, arraigando en los intereses materiales de las clases. De ese modo, nos permite entender en complejidad un hecho político puntual (en este caso, el golpe de Estado de septiembre de 1973), encontrando detrás de él una colorida paleta de contradicciones, cuya expresión relativamente autónoma en los campos de la ideología y la política, nos permite comprender la forma en que se constituyen los sujetos políticos al calor de la lucha de clases.

En "Dialéctica del proceso chileno: 1970-1973" es desarrollado un estudio minucioso de las clases sociales y de las contradicciones de clase, que no se restringe solamente al estudio de los sectores dominantes, sino que comprende también a las clases subalternas y su vocación de poder, construyendo de ese modo un análisis de carácter integral sobre la historia política chilena, desde comienzos del siglo XX hasta la década del setenta. No nos resulta llamativo que ello suceda. Creemos que la especificidad de la historia de Chile permite al sociólogo ecuatoriano llevar a cabo una lectura en complejidad de aquellos fenómenos. Pues las características de la formación económico-social chilena facilitan su labor investigativa, ya que allí se refiere a una nación donde la clase obrera se constituyó muy tempranamente como sujeto político, y construyó también de manera precoz sus herramientas organizativas. A eso debemos agregar que, a diferencia de la mayor parte de los países latinoamericanos, se constituyeron allí verdaderos partidos políticos de izquierda con arraigo en las masas.

En resumidas cuentas: creemos que la densidad en la historia, el desarrollo y la lucha política de la clase trabajadora chilena -desplegada a través de sus organizaciones sindicales y políticas- permitieron a Cueva la realización en complejidad de un análisis sociopolítico

\footnotetext{
${ }^{26}$ Esa definición del concepto de Estado es acuñada por Lenin en "El Estado y la revolución" en función de ciertas apreciaciones sobre el fenómeno estatal que recoge, fundamentalmente en el primer capítulo, de textos clásicos de Engels. Con más precisión, para realizar la caracterización que allí presenta, Lenin se basa fundamentalmente en las afirmaciones hechas por Engels en su clásico libro titulado "El origen de la familia, la propiedad privada y el estado". Véase Lenin, Vladimir I., El Estado y la revolución, Buenos Aires, Nuestra América, 2006 y Engels, Federico, El origen de la familia, la propiedad privada y el estado, Buenos Aires, Nuestra América, 2011.

${ }^{27}$ Cueva, Agustín, "Dialéctica del proceso chileno: 1970-1973", en Teoría social y procesos políticos en América Latina, México, Edicol, 1979, p. 119.
} 
sobre la realidad de aquel país, facilitando cierta armonía entre la utilización de las herramientas teóricas marxistas y la comprensión de la especificidad nacional chilena.

\section{Contrastes nacionales: el camino hacia América Latina}

A través de la reposición de los análisis sociopolíticos sobre Ecuador y Chile y las herramientas teóricas puestas en juego en ellos, intentamos esbozar una diferencia sustantiva entre los estudios de Cueva sobre ambos países. Si bien los trabajos acerca de Ecuador resultaron varios, y al ser parte de una preocupación sostenida del autor alcanzaron así cierto nivel de sistematicidad, se encontraron con un duro escollo a la hora de explicar la imposibilidad de los sectores populares para construir, en términos gramscianos, una voluntad colectiva nacional-popular. Aparece allí el velasquismo como el fantasma que sobrevuela e interrumpe esa tarea histórica. La concepción de ese fenómeno político como un "medio de manipulación de masas" es expresiva de aquel dilema. En definitiva, esa categorización da cuenta de un movimiento popular que, desde el punto de vista de Cueva, no se encuentra en condiciones de erigirse en artífice de su propio destino. Y por lo tanto, termina resultando víctima de una figura política que no contribuye a su constitución autónoma como sujeto político, ni a la construcción y desarrollo de fines que promuevan la superación del orden social. Mas el nudo de esa explicación en nuestro autor reside en el sujeto que funciona como respaldo del proceso velasquista: el subproletariado. El autor de "El proceso de dominación política en Ecuador" la ve como una clase bastarda, que desvía y distorsiona las contradicciones sociales de su antagonismo principal, permitiendo la emergencia de una solución política, deficientemente abordada en su dimensión teórica en el transcurso del libro: el populismo ${ }^{28}$. Como dijimos más arriba, el desarrollo analítico del velasquismo y su base subproletaria contrasta con la escasa indagación en la historia de las clases subalternas ecuatorianas (obreros -fabriles y rurales- y campesinos) y de los partidos y organizaciones de izquierda en ese país.

Nuevamente, no resulta difícil detectar la abismal diferencia entre aquella débil indagación acerca de los sectores populares ecuatorianos y la desplegada -condensada tan solo en un artículo- sobre el proceso político chileno. Su cercanía con respecto a la tradición comunista encontró sin dudas en Chile un caso nacional donde la clase obrera contaba con centrales sindicales fuertes, pero, ante todo, con partidos de inspiración marxista cuyo arraigo en el movimiento obrero y otros sectores del mundo popular probablemente haya sido uno de los más notables en la historia de la región.

\footnotetext{
${ }^{28}$ En "El proceso de dominación política en Ecuador" Cueva no desarrolla teóricamente el concepto de "populismo". Más bien realiza un análisis del velasquismo como su expresión. Recién en un texto dedicado a polemizar con Ernesto Laclau, titulado "El populismo como problema teórico y político", incluido en el volumen "Las democracias restringidas de América Latina", va a exponer una lectura teórica sobre el populismo. Véase Cueva, Agustín, "El populismo como problema teórico y político", en Las democracias restringidas de América Latina, Quito, Planeta. 1988.
} 
Creemos, por lo tanto, a través de esta comparación, que hubo en el caso ecuatoriano elementos que Cueva "no pudo ver", seguramente porque las condiciones que hubieran potenciado sus análisis sobre el movimiento popular, no estaban presentes en ese país. Esa ausencia, no impidió que principalmente en "El proceso de dominación política en Ecuador" -aunque también en otros escritos sociopolíticos menos extensos sobre ese país- existiera un detallado estudio sobre la relación entre Estado y clases sociales. Tal es así que en aquel libro es empleado con precisión y rigurosidad todo un arsenal teórico, mediante la adopción de categorías como "equilibrio inestable y precario", "bloque en el poder", "vacío de poder", "crisis de hegemonía" y "crisis política" - entre otros conceptos-, que es de suma utilidad para la producción de estudios desde la sociología política. Sin embargo, no podemos dejar de reconocer que a la hora de comprender el vínculo entre Estado y sectores subalternos fundamentalmente en sus hipótesis sobre el velasquismo- sus análisis derivaron en conceptualizaciones que, desde nuestro punto de vista, no resultan del mismo valor.

Esa crítica al abordaje del velasquismo, nos remite a un interesante aporte que realizara Luis Verdesoto acerca de la obra de Cueva. Aquel intelectual ecuatoriano, lleva a cabo una comparación entre las producciones teóricas de nuestro autor y las del boliviano René Zavaleta. En las diferencias entre ambos intelectuales, Verdesoto ve cristalizadas las distancias que separan a la historia de sus dos países de origen: Bolivia y Ecuador. El primero, plenamente indígena, y protagonista de una de las revoluciones nacionalistas más rutilantes en la historia de la región: la revolución boliviana de $1952^{29}$. El segundo, decidida pero inconclusamente mestizo, y seriamente dificultado para construir una identidad nacional desde los sectores subalternos, más allá de la construida por las clases dominantes a partir de la inserción subordinada de Ecuador en el sistema económico mundial. Así lo expresa Verdesoto:

En suma, los dos muestran a las sociedades que los gestaron como intelectuales. De un lado, un Ecuador fuertemente mestizo que, sin reconocer a esta relación como fundante, sólo alcanzó a diseñar su identidad en sentido negativo. La forma nacional es básicamente ser eslabón de la cadena imperialista. De otro lado, una Bolivia fuertemente india, que se reconoce como "nación en construcción", situación que se constituye en el parámetro de conocimiento y acción política ${ }^{30}$.

Si bien ambos autores parten de un cuestionamiento a la definición de Nación como una colectividad identitaria, creemos que las historias de los países que los vieron nacer, y a las que destinaron esfuerzos explicativos, influyeron notoriamente en su formación como intelectuales. Es interesante señalar que tanto Cueva como Zavaleta, al problematizar

\footnotetext{
${ }^{29}$ Recordemos en este sentido que Zavaleta (1937-1984) no fue ajeno a ese proceso político. Como ejemplo de su involucramiento en la revolución nacionalista, basta señalar que fue diputado en 1962 y Ministro de Minas en 1964.

${ }^{30}$ Verdesoto, Luis, "Hacia una relectura de Agustín Cueva", en 500 años historia actualidad y perspectiva. Seminario Agustín Cueva Dávila, Cuenca, Universidad de Cuenca-Facultad de Filosofía-CONUEP-ILDIS, p. 20.
} 
teóricamente la cuestión nacional, parten de una crítica a la misma definición de Nación, la de Joseph Stalin. Tanto Cueva en el artículo "Cultura, clase y Nación" como Zavaleta en su texto "La burguesía incompleta" discuten con la siguiente definición de Nación elaborada por Stalin: "Nación es una comunidad humana estable, históricamente formada y surgida sobre la base de la comunidad de idioma, de territorio, de vida económica y de psicología, manifestada ésta en la comunidad de cultura"31. Pero mientras el boliviano buscó incansablemente en los planos de la teoría y la política el modo en que las clases populares de su país podían constituir el proyecto de Nación que las clases dominantes habían dejado inconcluso, el ecuatoriano no llegó a abordar en densidad el problema de la construcción nacional, más allá de la conformación de condiciones objetivas necesarias (fuerzas productivas y mercado interno) para convertirse en un país plenamente capitalista.

Asimismo, Verdesoto relaciona en ese sentido el vínculo que cada uno de esos autores desarrollara entre Nación y América Latina. Zavaleta, desde sus primeros trabajos hasta su temprana partida física, se dedicó transversalmente al abordaje del problema nacional. Tal puede comprenderse como el eje articulador de su obra. Mientras que Cueva, como hemos señalado hasta aquí, se abocó en la primera etapa de su pensamiento -hasta el promedio de los años setenta- a estudiar diversos fenómenos relacionados con la realidad ecuatoriana. Una indagación que luego sería desplazada por interrogantes de carácter latinoamericano, seguramente como consecuencia del impacto que significó su encuentro en México con numerosos intelectuales de la región que residían en la academia de ese país (y principalmente, en la prestigiosa UNAM). Consideramos a las siguientes palabras de Verdesoto - a propósito de la comparación entre los dos autores referidos- como una suerte de prólogo de la etapa de "latinoamericanización" en la obra de Cueva que se abriría en la segunda mitad de los años setenta, en la que su mirada ya no estará enfocada sobre Ecuador, sino sobre América Latina, su historia, y sus principales dilemas como "contradictoria unidad":

Es sugerente pensar en los itinerarios intelectuales respectivos o cómo llegan a América Latina como objeto de pensamiento. Para Agustín Cueva, en los momentos intermedios de su producción intelectual, la posibilidad de volver la mirada finalmente hacia su país pasaba por "constituir" el objeto de investigación América Latina. Este trabajo significó una ruptura con sus antecedentes de investigación y, muchas veces, lo subsumió impidiéndole el retorno, aspiración implícita en la comunidad nacional. Tal vez, al final, quedó más constituido como objeto de trabajo América Latina que Ecuador, cuya pertinencia fue ser objeto de comparaciones en investigaciones regionales desde la perspectiva del adelanto o del retraso ${ }^{32}$.

\footnotetext{
${ }^{31}$ Stalin, Joseph, citado en Cueva, Agustín, "Clase, cultura y Nación”, en La teoría marxista. Categorías de base y problemas actuales, Quito, Planeta, 1988, p. 138, y citado en Zavaleta, René, "La burguesía incompleta", en Clases sociales y conocimiento, La Paz, Los amigos del libro. 1988, p. 160.

${ }^{32}$ Verdesoto, op. cit., p. 20.
} 
Si bien sus escritos dedicados al estudio de la realidad ecuatoriana tendrán una fuerte influencia en su formación intelectual y en su producción teórica posterior, Ecuador quedará relegado como objeto de estudio. Agustín Cueva adquirirá un verdadero renombre a nivel regional a través de sus célebres trabajos sobre América Latina. En cualquier caso, esperamos que estas páginas hayan sido de utilidad para iluminar una parte de su obra que creemos, vale la pena volver a indagar.

\section{Bibliografía}

-Báez, René, "Presentación”, en Autoritarismo y fascismo en América Latina, Quito, Centro de Pensamiento Crítico, 2013.

-Beigel, Fernanda, Agustín Cueva: Estado, sociedad y política en América Latina, Quito, Casa de la Cultura Ecuatoriana, 1995.

-Beigel, Fernanda, "Política, ideología y literatura en la obra de Agustín Cueva", en Fernández, Estela María (Comp.), Itinerarios del socialismo en América Latina, Córdoba, Alción Editora, 2001, pp. 183-194.

-Cueva, Agustín, "Chile”, en VV.AA., Radicalización y golpes de estado en América Latina, México, UNAM, 1973.

-Cueva, Agustín, El proceso de dominación política en Ecuador, México, Diógenes, 1974.

-Cueva, Agustín, "Crisis del capitalismo y perspectivas del nacionalismo en América Latina (análisis del caso ecuatoriano)", en Revista Mexicana de Sociología, Año XXXVIII, Vol. XXXVIII, N4, octubre-diciembre, México, 1976, pp. 825-841.

-Cueva, Agustín, "Dialéctica del proceso chileno: 1970-1973”, en Teoría social y procesos políticos en América Latina, México, Edicol, 1979.

-Cueva, Agustín, "El marxismo latinoamericano: historia y problemas actuales", en Ideología y sociedad en América Latina, Montevideo, Ediciones de la Banda Oriental, 1988.

-Cueva, Agustín, "El populismo como problema teórico y político", en Las democracias restringidas de América Latina, Quito, Planeta. 1988.

-Cueva, Agustín, “Clase, cultura y Nación”, en La teoría marxista. Categorías de base y problemas actuales, Quito, Planeta, 1988.

-Cueva, Agustín, “La crisis de 1929-1932: un análisis", en VV.AA., Las crisis en el Ecuador: los treinta y ochenta, Quito, Corporación Editora Nacional-Centro de Estudios Latinoamericanos de la Universidad de Oxford-Instituto de Estudios Avanzados, 1991. 
-Engels, Federico, Del socialismo utópico al socialismo científico, Buenos Aires, Anteo, 1986.

-Engels, Federico, El origen de la familia, la propiedad privada y el estado, Buenos Aires, Nuestra América, 2011.

-Gramsci, Antonio, “Apuntes sobre la historia de las clases subalternas. Criterios metódicos”, en Escritos políticos (1917-1933), México, Siglo XXI.

-Lenin, Vladimir I., El Estado y la revolución, Buenos Aires, Nuestra América, 2006.

-Marx, Karl, El 18 Brumario de Luis Bonaparte, Buenos Aires, Prometeo, 2003.

-Sosa Elizaga, Raquel, “Agustín Cueva en la memoria”, en Ruy Mauro Marini y Márgara Millán (Coord.), La teoría social latinoamericana. La centralidad del marxismo, México, Ediciones El Caballito, Tomo III, 1995.

-Tinajero, Fernando, "Agustín Cueva, o la lucidez apasionada”, en Agustín Cueva. Ensayos sociológicos o políticos, Quito, Ministerio de Coordinación de la Política y Gobiernos Autónomos Descentralizados, 2012.

-Verdesoto, Luis, "Hacia una relectura de Agustín Cueva", en 500 años historia actualidad y perspectiva. Seminario Agustín Cueva Dávila, Cuenca, Universidad de Cuenca-Facultad de Filosofía-CONUEP-ILDIS.

-VV.AA., Ecuador: pasado y presente, Quito, Libresa, 1995.

-Zavaleta, René, "La burguesía incompleta”, en Clases sociales y conocimiento, La Paz, Los amigos del libro. 1988

-Zavaleta, René, "El Estado en América Latina”, en El Estado en América Latina, La Paz, Los amigos del libro, 1990. 